\title{
Transparency and Trust in Government (2007-2014): A Comparative Study
}

Vincent Mabillard, Martial Pasquier

\begin{abstract}
This article exposes contemporary approaches to transparency and trust. It explores the links between the two concepts in 10 countries between 2007 and 2014, using open-data indexes and access-to-information requests as proxies for transparency. So far, most studies have focused on conceptual models, specific aspects of transparency in particular case studies or have compared legal frameworks from different countries. Here, data about citizens' requests to get access to administrative documents have been gathered. This dataset, combined with existing indexes on open data and government, has enabled us to establish a national ranking, particularly useful in a comparative perspective. Data about trust have been collected from reports published by international organisations. Key findings prove that there is no sharp decline of trust in government in all countries considered in this article. They also tend to show that transparency and trust in government are not systematically positively associated. Therefore, this article challenges the common assumption, mostly found in the normative literature, about a positive interrelation between the two, where trust in government is conceived as a beneficial effect of administrative transparency. Finally, it suggests that mis(trust) may be considered a key driver of transparency and would as such call for more transparency from public bodies.
\end{abstract}

\section{Keywords}

Transparency, freedom of information, open data, trust in government, public administration

\section{Introduction}

The link between transparency and ethics seems rather straightforward: as organisations are held accountable and citizens have access to information, which may 
directly affect their lives, transparency enhances the ethical nature of public institutions (Rawlins 2009). In this sense, the exposure of public actions is supposed to eliminate the problem of moral hazard (Stasavage 2003). Based on first reflections developed by famous philosophers of the $18^{\text {th }}$ century, such as Rousseau, Kant and Bentham, transparency is conceived as a fundamental right and a moral imperative for citizens to get access to information detained by the authorities. Following Bentham's idea of the Public Opinion Tribunal (see Bozzo-Rey 2011), Sullivan (1965, 428) affirms that "each person has a right to true information in matters which affect him [and] has a right to participate in decisions which affect him." Therefore, the moral essence of transparency lies in the fact that citizens have a right to information, which in turn allows them to evaluate the relevance of the processes and the decisions made by public organisations. The European Commission fully agrees with this idea, as highlighted by its transparency portal, which is designed to help citizens to "be better informed and better prepared to follow and participate in the EU decision-making process, to enjoy [their] rights and to play [their] role as a European citizen to the full."

Trust in government is also increasingly seen as a key component of democracy. In this sense, contemporary literature assumes that any government needs citizens' trust if it is to work well (Hardin 1999). As a result, institutions have focused more and more on the levels of citizens' trust in government. In the United States, polls about public trust in government date back to 1958, while European surveys have emerged more recently. In both cases, the preoccupation is driven by the same factors: electoral considerations and satisfaction with the government, but also the confidence of investors and consumers and the success of governmental policies which require cooperation and compliance from the citizens. ${ }^{2}$ As there is a growing feeling of decline of trust in the public sector (Van de Walle et al. 2008), this article addresses the level of trust in government in 10 countries for the period 2007-2014.

If transparency has mainly been conceived as a moral imperative for democratic institutions towards their citizens, organisations themselves have also come to realise that transparency leads to solid bottom-line benefits in terms of reputation, possibly gaining more trust on the people's side. Starting from this assumption, transparency and trust have been associated positively by many governments, as exemplified by Obama's memorandum on transparency and open government, in which he insists on working together for implementing a system of openness and ensuring public trust. ${ }^{3}$ In the United Kingdom (UK), the governmental website dedicates a page to transparency issues, saying that it is necessary to strengthen

1 Available at http://ec.europa.eu/transparency/index_en.htm (last accessed 15 January 2016).

2 Available at http://www.oecd.org/gov/trust-in-government.htm (last accessed 12 January 2016).

3 Available at https://www.whitehouse.gov/the_press_office/TransparencyandOpenGovernment (last accessed 18 January 2016). 
people's trust in government. ${ }^{4}$ The OECD promotes transparency as a remedy for trust, correlating positively both concepts with economic growth. ${ }^{5}$ Nevertheless, according to the academic literature, this optimistic view is not empirically proven and remains mostly normative.

This article seeks to go beyond this normative view. Using secondary data, it explores the association between transparency and trust in government. Two main questions arise: first of all, as advocated by the OECD, does greater transparency lead to greater trust? In other words, does transparency work as a driver to generate more citizen trust in their authorities? And secondly, did transparency initially emerge as a remedy for the lack of trust in government? Do low levels of government trustworthiness call for an ex-post mechanism of control and transparency?

Details about the definitions of transparency and trust will first be provided, focusing on their multi-faceted characteristics, as well as their use in multiple fields, including philosophy, political science, psychology, economy and law. Secondly, the relationship between the two concepts will be investigated in light of current research on the topic. Several studies have already suggested a paradoxical relation: on the one hand, transparency reduces the asymmetry of information and might increase trust in government. On the other hand, the lack of knowledge, resulting from such an asymmetry, is precisely the reason why citizens put their trust (including a part of faith) in their representatives. Using open-data indexes and access-to-information requests as proxies for transparency, the article investigates the relationship between disclosure of information, implications for the citizens and their level of trust.

\section{Transparency}

Just like many other notions in Public Administration research, transparency is a multifaceted concept, considered by some prominent scholars to be more often invoked than defined, and more often preached than practised (Heald and Hood 2006). In other words, it can have diverse meanings according to the context and the exact wording of its definition. It is also made up of different dimensions, which depend upon the type of transparency addressed. This preliminary remark is necessary, as we will focus on two specific forms of transparency and embrace a particular approach accordingly.

First of all, being transparent is mostly defined as being visible. Transparency is frequently opposed to opacity and secrecy, a position already defended by philosophers of the $18^{\text {th }}$ century, mainly as a reaction against political absolutism,

4 Available at https://www.gov.uk/government/topics/government-efficiency-transparency-andaccountability (last accessed 20 December 2015).

5 Available at http://www.oecd.org/governance/transparencytrustandgrowth.htm (last accessed 12 January 2016). 
which prevailed at the time (Hood 2006). The debate about the integrity of the state and the fight against conspiracy is still vivid nowadays, and administrative secrecy remains a key issue in contemporary governance. Transparency is often linked with accountability, in the sense that secrecy prevents any administration from disclosing information, therefore making it unaccountable to the general public because information and actions are deliberately hidden (Florini 1998). In a normative perspective, transparency is then considered a desirable good. The proactive disclosure of information by the government is labelled "active transparency" (Meijer et al. 2012). It involves all forms of deliberate communication about government decisions and activities, including press statements, information published on websites, brochures, official journals, etc. However, this broad definition is still insufficient, since "disclosure, alone, can defeat the purpose of transparency. It can obfuscate, rather than enlighten" (Rawlins 2009, 74). This last remark is in line with a recurrent critique of administrative transparency: the overload of information may turn the desirable goal of availability into a nightmare for the recipients of that information (Brin 1998; Curtin and Meijer 2006). Therefore, one should also pay attention to other types of transparency.

Secondly, freedom of information has increasingly been perceived as a fundamental human right. The idea was inscribed in the United Nations Charter in 1948, positively associated with peaceful coexistence and democracy, but was more related to the right to seek and pass on information. Regarding access to documents, a recommendation on access to documents was passed by the Council of Europe in 1981 (Birkinshaw 2006). At the country level, Sweden had already adopted a legislation on the matter in 1766, in parallel to the transition from Swedish absolutist to liberal bourgeois rule (Erkkilä 2012). Finland enacted a transparency legislation in 1951, followed by the Freedom of Information (FOI) law in the United States in 1966. Access-to-information (ATI) ${ }^{6}$ legislation gained popularity and even gained ground in 100 countries (McIntosh 2014). It allows citizens to submit requests to the administration in order to have access to documents, following procedures specific to each country. This kind of transparency is called "passive", as information is not proactively released by the authorities. Nevertheless, the idea of counteracting secrecy remains essential on the citizens' side. According to Pasquier and Villeneuve $(2007,149)$, documentary transparency enables "the public [to have] a legally guaranteed right of access to information held by the government, the main objective being to force public authorities to disclose what they would rather keep secret."

Two general types of transparency can be distinguished, which take three different forms (Meijer et al. 2012):

6 In this article, FOI refers to specific laws, because numerous countries use this designation. ATI refers to legislation in general, but both terms describe the same phenomenon: citizens can submit requests to obtain information about governmental actions and decisions with certain limitations, varying from country to country. 
1) Active release (disclosure on a proactive and voluntary basis);

2) Or passive release (via requests submitted by citizens, using for instance ATI legislation).

Both kinds of transparency are intentional in their objective to give citizens information about the workings of government. There is also a third way to increase transparency. It involves the unintentional access to government information: this kind of transparency refers to leaking and whistleblowing acts. It is considered by the authors as forced access to information, since disclosure of this type is mostly provoked by individuals and not controlled by the government.

In this article, forced transparency is not addressed, because its impact is rather diffuse and cannot be clearly measured. Moreover, it does not belong to the classic institutional relationship between the administration and the citizens, and is not mentioned in most studies about the effects of government transparency. Several studies also consider open meetings as a form of access to information, but they imply effective participation by the citizens, and in rather small numbers. According to Meijer et al. (2012), open access to decision-making arenas represents another dimension of open government, called voice (or participation), which can at times be an appropriate complement to vision (or transparency).

Our perspective focuses on the institutional relationship between the government and its citizens, in which the latter have the legal right to submit requests to get access to administrative documents. At the same time, a certain amount of information is also proactively disclosed by the authorities, with different levels of accessibility, as shown by the rankings presented below. This approach concentrates on the public bodies' perspective. However, it enables researchers to build their analysis on existing data and study how transparency and trust are associated.

\section{Trust}

So far, trust has mainly been addressed as a psychosocial aspect. Studied in diverse scientific fields (human sciences, philosophy, psychology, management, etc.), it is usually considered to have a positive impact on social relations (Giddens 1984). In spite of the consensus about beneficial effects of trust, there is no commonly agreed definition. In this respect, Blomqvist $(1997,271)$ affirms that "there is still a good deal of conceptual confusion [and] there has been no real conceptual development regarding trust, although, in some studies a definition of trust is given and in others merely implied." Before going deeper into the analysis of the data, a conceptual clarification should be made about trustworthiness, trust and confidence. Trustworthiness, like trust, is in essence relational, but in a more limited sense. It does not need any call for trust and rests upon the assurance of potential trusters that they will not be betrayed by the trusted party (Levi and Stoker 2000). Trust differs 
from trustworthiness in the sense that it refers to a judgment which reflects beliefs about the trustworthiness of the government. Confidence also differs from trust, as developed in a report from Adams (2005). Though often used interchangeably with trust, confidence is more often linked with reason and facts, while trust partially involves faith (Shaw 1997).

Research has focused on ties between individuals (interpersonal trust) and relationships between them, while studies connecting public administration to trust have remained rather rare (Bouckaert 2012; Edelenbos and Klijn 2007). Recently, there has been a growing interest in trust between public authorities and stakeholders in charge of carrying out public tasks, due to the new organisational forms observed and the limits of coordination mechanisms between these actors (Fivat and Pasquier 2014). It involves a bilateral kind of trust (inter partes), which would bolster cooperation. However, research on trust and institutions has traditionally been centred on relationships between an organisation and the citizens (Bouckaert and Van de Walle 2003; Carter and Bélanger 2005; Hardin 2013). In this perspective, trust is unilateral, because it is exclusively regarded from the citizens' side and directed towards public institutions. As direct relations between the citizens and institutions often remain sporadic, there is no need to consider a reciprocal, interpartes relationship between the two. Moreover, if trust has mainly been thought of as a relation between the citizens and public entities, it may also be possible to raise the issue of institutional trust (Zucker 1986). In this sense, citizens can have trust in principles emanating from institutions which ensure social interactions, such as trust in justice.

As mentioned above, the definition of trust still depends on the context, the type of relationship and the dimensions considered in the study. The same issue arises with the measurement of the citizens' level of trust in government. According to Fivat and Pasquier (2014), dimensions used to conceptualise inter-organisational trust could also be used to measure citizens' trust in government. Following preliminary work from Sako and Helper (1998), trust is based on expectations and divided into three dimensions:

1. Competence (is the other party capable of doing what they say they will do?);

2. Contractual (will the other party carry out their contractual agreement?);

3. Good-will (will the other party make an open-ended commitment to take initiatives for mutual benefit while refraining from unfair advantage taking?).

These dimensions are considered by Sako and Helper (1998) to be three different types of trust, because they refer to diverse expectations. However, other approaches distinguish trust from perceived trustworthiness, focusing on specific factors, including ability, benevolence and integrity (Mayer et al. 1995), or other dimensions such as reliability, predictability and fairness (Zaheer et al. 1998). Most institutions (e.g. the European Union) do not take all these dimensions into account 
and usually only ask citizens about their general level of trust in government. ${ }^{7}$ In spite of this lack of precision, this article does use such data from supranational institutions, because it is the only way to be able to compare the evolution of levels of trust with transparency in the countries covered in this study.

\section{Linking the two concepts}

In the normative literature, trust is usually seen as a beneficial effect of transparency, sometimes assuming that both concepts mutually reinforce each other (Brown et al. 2014). Many FOI laws find their legitimacy in the expected increase of trust, as is the case in Switzerland: "the principle of freedom of information ... contributes to keeping the public informed by allowing all citizens access to official documents, thereby increasing confidence in the state and authorities." In the European Union (EU), the link between transparency and trust has been formally established in the adoption process of the Maastricht Treaty (Lenaerts 2004). On this occasion, it has been said that "the Conference considers that transparency of the decision-making process strengthens the democratic nature of the institutions and the public's confidence in the administration." Therefore, the desire to increase trust in government has been a key driver for implementing documentary transparency (Worthy 2010). This assumption is underpinned by the idea that information asymmetry between the state and the citizens must be reduced to empower the citizens. With more information available, the latter will be able to better evaluate the institutions and make more informed decisions about policy choices. However, understanding seems to be at least as important as availability of information, because less understanding may lead to less trust (Strathern 2000).

According to Zand (1971), trust is not an emotion or a global feeling, but rather the regulation of one's dependence on another, in a relational perspective. It is necessary since trust rests on an incomplete exchange of information (Blomqvist 1997). This remark makes a study between transparency and trust relevant. Indeed, if one has trust in a particular organisation or system because of a lack of knowledge, resulting from the asymmetry of information, what happens if greater transparency reduces the gap? According to Hardin (2013), current low levels of government trustworthiness in the citizens' perceptions are the direct consequence of this lack of knowledge. However, as mentioned by Möllering $(2013,54)$, "the reason Hardin gives for why citizens should be unable to trust government is exactly the reason why they have a need to trust government: their lack of knowledge." The

7 See for instance Standard Eurobarometer 80 (2013). Available at http://ec.europa.eu/public opinion/archives/eb/eb80/eb80_first_en.pdf (last accessed 13 January 2016).

8 Available at http://www.edoeb.admin.ch/oeffentlichkeitsprinzip/00887/00888/index. html?lang=en (last accessed 4 January 2016).

9 All details about the Conference and the annexes to the Maastricht Treaty are available at http:// aei.pitt.edu/2944/1/2944.pdf (last accessed 17 November 2015). 
debate between the two authors suggests that transparency and trust do not have a linear relation and that a degree of uncertainty is necessary for trust to exist. One could therefore suppose that full secrecy would lead to mistrust, while full transparency would create a situation of constant distrust, but such hypotheses remain to be shown empirically. Moreover, this debate leads to two main questions (Fivat and Pasquier 2014):

1. Does greater transparency lead to greater trust? In other words, does more information disclosed by the state increase government trustworthiness and citizens' trust in government?

2. Did transparency emerge as a remedy for the lack of trust in government? Is it working as an ex-post mechanism of control, because of initial low levels of government trustworthiness?

This article will address the two questions, using data from the European barometers for EU member states and OECD for other countries, as there is no standardised dataset for all countries.

\section{Methods}

Methodologically, transparency is considered here both in its active and passive forms. In this sense, data about government openness (proactive disclosure of information to the public) are combined with requests submitted by citizens to access official documents held by the administration (through FOI laws). Passive access to information is an essential part of transparency, since governments do not release every document on a voluntary basis, and in spite of the development of ATI legislation, secrecy remains a common practice within administrations (Pasquier and Villeneuve 2007). Although this new right is hardly used in several countries, we argue that the existence and usage of FOI laws contributes to creating a more transparent environment, and this dimension should therefore be included in any measure of transparency. Countries considered in this study keep a public record of the number of requests submitted to the administration at the national level and make them available on specific websites dedicated to ATI. The list includes the United States (US), Australia, Canada, Mexico, the UK, Ireland, New Zealand, India, Switzerland and Germany. A first and partial study on such data has been conducted by Holsen (2012), but the author takes fewer states into account than is done here and does not allow for a comparison of the number of requests for the period 2007-2014, as is done here. Regarding active transparency, data published by the OECD focus on government openness, taking into consideration the chief information officers, while civil-society organisations turn their attention to open data (about, e.g., national statistics, government budget, legislation) from a user's perspective. This is especially the case for the Global Open Data (GOD) Index, which will be consid- 
ered in our study. ${ }^{10}$ Transparency as measured here results in a national ranking of the selected countries. States are ranked according to their relative score in all three categories (the number of ATI requests submitted, the OECD ranking on open government data and the GOD index).

With regard to levels of trust in government, data about the countries mentioned above come from two datasets: Eurobarometers and the OECD. The latter is based on the Gallup World Poll, which provides data on a yearly basis. The reports published by the OECD present the evolution of trust in government between 2007 and 2014. However, data about government openness are not available for this period. To test the association between transparency and trust in government, data about trust in government in 2014 have been combined with our national ranking of transparency.

\section{Access-to-information requests}

This section is based on a study carried out by Pasquier and Holsen (2009). According to them, the current praise for ATI legislation results from a global campaign from journalists, civil-society groups and international non-governmental organisations (NGOs). A "transparency revolution" has been growing in the last few decades because of two main motivations: the increase of the public bodies' accountability towards their citizens (possibly generating greater trust in government) and the empowerment of the citizens, who make better informed decisions (and possibly participate more in the political process).

Even though ATI legislation varies in the different countries that have adopted such legislation, and processes can take diverse forms, the main objectives are often similar. Governments claim that the public can obtain information and use it to verify that they work in the citizens' interests. From a philosophical point of view, Bentham directly connects secrecy with conspiracy and thus affirms that public officials will be less tempted to misuse power because of external monitoring (Hood 2006). Despite such support, coming from both the governments and the citizens, one can note that, in some countries, there has been relatively low usage of the new legislative instruments so far. Although the capacity to obtain more information about government through legal processes intuitively implies more transparency, two limitations remain: firstly, ATI requests are mainly submitted by journalists, lawyers, and interest groups in certain countries. Secondly, the lack of interest or complex procedures have led to the low usage of ATI mentioned just above. Consequently, greater access to governmental and administrative information may create a more transparent environment, but a real increase of transparency would probably involve more citizen participation. Table 1 shows how requests have evolved over the last few years.

10 Available at http://index.okfn.org/place/ (last accessed 14 January 2016). 


\section{Table 1}

Evolution of the number of ATI requests (per 1000 inhabitants), 2007-2014

\begin{tabular}{|l|c|c|c|c|c|c|c|c|}
\hline & $\mathbf{2 0 0 7}$ & $\mathbf{2 0 0 8}$ & $\mathbf{2 0 0 9}$ & $\mathbf{2 0 1 0}$ & $\mathbf{2 0 1 1}$ & $\mathbf{2 0 1 2}$ & $\mathbf{2 0 1 3}$ & $\mathbf{2 0 1 4}$ \\
\hline US & N/A** & 1.99 & 1.68 & 1.93 & 2.07 & 2.07 & 2.23 & 2.24 \\
\hline Australia & 1.83 & 1.35 & 1.26 & 0.97 & 1.05 & 1.08 & 1.07 & 1.21 \\
\hline Canada* & 0.88 & 0.95 & 1.01 & 1.03 & 1.21 & 1.24 & 1.57 & 1.69 \\
\hline Mexico & 0.84 & 0.92 & 1.01 & 1.03 & 1.02 & 1.07 & 1.19 & 1.20 \\
\hline UK & 0.54 & 0.57 & 0.65 & 0.70 & 0.75 & 0.78 & 0.81 & 0.73 \\
\hline Ireland & 0.24 & 0.37 & 0.42 & 0.41 & 0.33 & 0.48 & 0.38 & 0.43 \\
\hline $\begin{array}{l}\text { New } \\
\text { Zealand }\end{array}$ & 0.19 & 0.21 & 0.19 & 0.21 & 0.23 & 0.28 & 0.53 & 0.27 \\
\hline India & 0.15 & 0.22 & 0.27 & 0.43 & 0.33 & 0.50 & 0.63 & 0.64 \\
\hline Switzerland & 0.03 & 0.03 & 0.03 & 0.03 & 0.06 & 0.06 & 0.06 & 0.07 \\
\hline Germany & 0.02 & 0.02 & 0.02 & 0.02 & 0.04 & 0.08 & 0.06 & 0.11 \\
\hline
\end{tabular}

* In Canada and India, requests are based on the fiscal year, running from 1 April to 31 March; in the United States, fiscal year runs from 1 October to 30 September; in New Zealand and Australia from 1 July to 30 June. All other collected data are calendar-year based.

** There is no data for the US in 2007 , because new reporting requirements were introduced in 2008, limiting FOIA annual reports only to access requests that involve use of the FOIA. In 2007, the absolute number of requests reported peaked at 21,758,651 (72.24 per 1000 inhabitants).

The number of ATI requests depicted above excludes requests made by phone, email, etc. and those submitted at sub-national levels, using for instance ATI state/cantonal laws in federal states. A typical example can be found in Switzerland, where cantons have adopted transparency laws at different times. Bern was the first to legislate on the matter (the law was adopted in 1995), then followed by 14 cantons between 2001 and 2011 (Meilland 2013). A transparency law at the federal level (Ltrans) was voted on in 2004 and enforced two years later. In some decentralised states, ATI legislation exists at sub-national levels and could give another picture of passive transparency.

A brief analysis of the data shows that there has been a global increase of requests submitted in all countries considered in this article, but at a different rate. The only exception is Australia, where the number of requests was higher in 2007 compared to 2014, though it has been increasing again since 2011. In some countries, there is a constant increase for the whole period 2007-2014, whereas others have witnessed a more or less slight decrease in the last 2-3 years. For instance, requests submitted in New Zealand almost doubled between 2012 and 2013, but the administration received almost the same amount in 2014 as in 2012 . In the UK, 
there were 5,000 requests less in 2014 compared to the year before, while until then the amount of requests had been constantly growing since 2007 .

Explanations about the usage of ATI vary according to the context. Institutional and historical factors, together with timing issues, may help to better understand why citizens have welcomed and used ATI legislation in diverse ways. In Switzerland, the recent character of the law leads to a poor level of publicity and knowledge and does not attract much interest in the population (Pasquier and Holsen 2009). Moreover, the Swiss political system of "concordance" (consensus system) and semi-direct democracy, including referendum and popular-initiative rights, provides citizens with other avenues to information. The consultative system and "militia" politics (deputies are not professional politicians and keep a professional activity) are also important factors. This unique feature of the Swiss system has an impact on citizens, especially journalists, who mainly use the Ltrans for professional purposes: they seem to use it less frequently than their British fellows, who have additionally been trained to do so (Pasquier and Holsen 2009). Legislation in Switzerland does not allow citizens to have access to documents completed before the enforcement of the law, while a retrospective law is in place in other jurisdictions, such as the UK, Australia and Scotland. On a more practical level, individuals have sometimes experienced difficulties filing a request or have complained about deficient instructions, in particular in the Indian countryside (Roberts 2010). Some hypotheses have been explored theoretically about ATI requests in some countries, especially Switzerland and the UK (Pasquier 2009; Worthy 2010), but a systematic study on the matter is still missing (Hazell et al. 2009; Holsen 2012; Roberts 2010).

\section{Levels of trust in government}

In this article, the concept of trust is used, as the term includes asymmetry of information. In the absence of total disclosure of information, it seems impossible to reach a full understanding of facts. As a result, a part of faith must be placed by citizens in governmental decisions and actions. Moreover, the notion of trust is mostly used in the datasets considered for our study. In the case of Gallup polls and their use by the OECD, trust and confidence are mixed up, as trust is measured through a rate of confidence in government. 
Table 2

Evolution of trust in government, 2007-2014 (in \%)

\begin{tabular}{|l|c|c|c|}
\cline { 2 - 4 } \multicolumn{1}{c|}{} & $\mathbf{2 0 0 7}$ & $\mathbf{2 0 1 4}$ & $\mathbf{2 0 0 7 - 2 0 1 4}$ \\
\hline Canada* & 64 & 46 & -18 \\
\hline Ireland & 32 & 23 & -9 \\
\hline UK & 30 & 31 & +1 \\
\hline US & 39 & 35 & -4 \\
\hline Germany & 40 & 48 & +8 \\
\hline Switzerland & $63 * *$ & 75 & +12 \\
\hline India & 82 & 73 & -9 \\
\hline Mexico & 42 & 33 & -9 \\
\hline New Zealand & 59 & 63 & +4 \\
\hline Australia & 53 & 45 & -8 \\
\hline
\end{tabular}

* Data for non-EU member states come from OECD reports, based on Gallup polls. The question asked is "Do you have confidence in national government?" Data refer to those who answered "yes". In Eurobarometer's surveys, the question is formulated in these words: "Do you tend to trust the government?" Data refer to those who answered "tend to trust".

** 2006

These are the only data about trust in government which allow to carry out a comparative study on a yearly basis. Other datasets exist, but do not include all countries considered in this article or do not have surveys conducted every year. For instance, the World Values Survey (WVS) dataset remains fragmented. Data from the WVS are available for multiple-year periods (as opposed to Gallup polls) and cover only 25 OECD countries. All countries considered in this study (all states which have made the number of requests through ATI legislation public) are not present in the WVS dataset. It seems difficult to compare the data, since the survey questions and the answering categories differ strongly from one dataset to the other. ${ }^{11}$ A systematic analysis would require the establishment of a unique dataset with full access to the data, conducted every year and including all countries for which ATI requests are available. However, general tendencies can be drawn from these polls. As depicted in Table 2, and in other surveys, there is no global decrease of trust in government in the world for the period 2007-2014. Strong variations, depending on the context, remain the norm in a comparative perspective. Just to give an example, trust in government in Germany has risen from $40 \%$ to $48 \%$ be-

11 Wording of the WVS question is: "how much confidence do you have in the government?" with four different choices of answers: a great deal/quite a lot/not very much/not at all. The Edelman Trust barometer includes a nine-point scale, ranging from "do not trust at all" to "trust them a great deal". 
tween 2007 and 2014, or from $22.7 \%$ to $44.4 \%$ between 2006 and 2013 according to the WVS. On the opposite side, in Mexico trust in government has dropped by 9 percentage points between 2007 and 2014, and by 5.2 points between 2005 and 2012 according to the WVS.

Since trust is a volatile concept, studied from various angles, it seems impossible to give a precise explanation of the variations shown above. A global analysis of trust would involve economic, political, social and individual factors. Determinants of trust are numerous but never investigated in the surveys carried out on a large scale. Moreover, in strongly polarised bipartisan systems, such as the US, identification with a party plays a significant role in the way citizens tend to trust the government or not (Levi and Stoker 2000). The analysis could even be extended to individuals in a strong presidential system or authoritarian regimes. Therefore, a comprehensive study of trust levels requires national analyses, because context matters enormously. For instance, contextual events such as the Vietnam War or $9 / 11$ in the US have impacted trust in government in a specific way. Though it may be possible to isolate a variable in a comparative perspective, such as the financial crisis, it remains difficult to study trust in all its components across all countries. The main key finding that we would like to draw from this issue is the fact that no global decrease of trust in government has been observed in the last few years, but that levels of trust in government strongly vary according to the states considered.

\section{Disclosure, access to information, and trust in government}

This section deals with the association between transparency and trust in government. Using the data presented so far, it aims to give an answer to the questions mentioned above: does more administrative transparency bring about more trust from the citizens? And does transparency result from low levels of trust in government? These two questions show the ambiguity of the relationship between the two concepts. On the one hand, it is hypothesised that transparency has an effect on trust, always perceived by practitioners as being positive (Grimmelikhuijsen 2012). On the other hand, trust in government can also be a driver of transparency, not only an objective, depending on the theoretical approach selected (Bouckaert 2012). In this sense, initial levels of trust can foster transparency reforms, because people are more willing to open themselves and government activity to public scrutiny if levels of trust are high. On the citizens' side, high or low levels of trust may positively or negatively affect individual perceptions of administrative transparency. According to Mabillard and Pasquier $(2015,27)$, "one could argue that trust in government is also a prerequisite to believe in the information gathered. In other words, faith of a person is indispensable to believe what the other person says in the first place."

It has already been said that this article addresses primarily passive transparency, focusing on access to information requests under ATI legislation. Although 
this parameter can be used as a proxy, one may also take into account the active form of transparency, a concept closer to the notion of disclosure. Both types of transparency are part of a bigger movement towards openness, resulting from a need to reduce information asymmetry between the administration and the population in an information society (Pasquier 2013). This objective becomes even more crucial with the development of new technologies. In this context, many interests groups and organisations, like Open Government Data ${ }^{12}$, promote the free access to official documents online. Several governments have responded to this movement with the creation of open data portals, where datasets are made available to the public. This kind of active transparency attracts most attention from the citizens, the civil society and the governments together. Open government, including open data, can also be used as a proxy to measure transparency, even though transparency itself does not include participation in all definitions (see Meijer et al. 2012). In order to do so, two other datasets will be considered in this article: the GOD, although there is no data available for New Zealand in 2015, and the OECD survey on open government data (OECD 2015), despite the fact that only OECD countries appear on the list, thus excluding India.

The GOD includes 122 states and takes into account 13 variables to establish its ranking. All these variables, such as national statistics and legislation, consists of the same 9 dimensions, including, for example, openly licensed, machine-readable, free and up-to-date information. States obtain a certain percentage according to how well they perform in the 9 dimensions. The OECD survey focuses on the following categories: data accessibility and availability on the national data portal and governments' efforts to support data re-use. Countries' scores are calculated on a 0 (lowest)-1 (highest) scale. Tables 3 and 4 show how the countries considered in this article score on both rankings.

In spite of the differences found in the rankings, a comparison of these two datasets shows that the UK/Great Britain and Australia are considered particularly committed to openness, while Germany, Switzerland and Ireland (in the same order) score especially low compared to the other countries selected in this article. As these data focus only on active transparency, which means proactive disclosure of information, one may also take into account passive transparency data presented above and compare them with GOD and OECD indexes. With respect to the number of requests submitted to the administration in 2014 (per 1000 inhabitants), US government agencies have received 2.24, Canada 1.69, and Australia 1.21. At the same time, Germany and Switzerland's scores remain low, at, respectively, 0.11 and 0.07 . One may wonder if countries such as the US, Australia, Canada and the UK have reached their stated goal of creating a "culture of transparency", while others have failed to do so, have not striven to achieve it or have not identified it as a funda-

12 Available at http://opengovernmentdata.org/ (last accessed 14 January 2016). 
mental issue. Other factors mentioned above, related to contextual particularities, lead us to leave this debate open.

Table 3

Global Open Data Index (2015), in \%

\begin{tabular}{|l|c|c|}
\hline \multicolumn{1}{|c|}{ Country } & Score & Rank (out of 122) \\
\hline UK & 76 & 2 \\
\hline Australia & 67 & 5 \\
\hline US & 64 & 8 \\
\hline Mexico & 58 & 13 \\
\hline Canada & 55 & 17 \\
\hline India & 55 & 17 \\
\hline Germany & 49 & 26 \\
\hline Switzerland & 47 & 29 \\
\hline Ireland & 46 & 31 \\
\hline
\end{tabular}

Mean: $57.4 \%$

GOD average: $33.3 \%$

Table 4

OECD Open government data Index (2015), on a 0 (lowest)-1 (highest) scale

\begin{tabular}{|l|c|c|}
\hline \multicolumn{1}{|c|}{ Country } & Score & Rank (out of 30) \\
\hline Great Britain* & 0.83 & 3 \\
\hline Australia & 0.81 & 4 \\
\hline Canada & 0.79 & 5 \\
\hline US & 0.67 & 9 \\
\hline Mexico & 0.66 & 10 \\
\hline New Zealand & 0.59 & 15 \\
\hline Germany & 0.55 & 16 \\
\hline Switzerland & 0.48 & 21 \\
\hline Ireland & 0.43 & 22 \\
\hline
\end{tabular}

* Data only available for Great Britain and not the UK

Mean: 0.65

OECD average: 0.58

Now turning to trust in government, how does this variable covariate with passive transparency? Once again, national particularities seem to play an enormous role, since data vary significantly from one state to another. For instance, there has been a sharp decrease of trust in government and a dramatic increase of 
requests submitted to Irish public bodies between 2007 and 2014, whereas Switzerland and Germany have experienced greater trust in government and a sharp rise in requests over the same period of time. The same analysis would apply to the other countries, with more or less strong variations according to the states considered. Therefore, it appears impossible to draw an association, whether positive or negative, between the evolution of levels of trust in government and the total number of ATI requests (passive transparency) in a comparative perspective. Data for all countries are summed up in Table 5.

Table 5

Evolution of trust in government (percentage points) and number of ATI requests per 1000 inhabitants (in \%), 2007-2014

\begin{tabular}{|l|c|c|}
\hline \multicolumn{1}{|c|}{ Country } & Trust in government & ATI Requests \\
\hline Canada & -18 & +92.0 \\
\hline Ireland & -9 & +79.2 \\
\hline UK & +1 & +35.2 \\
\hline US & -4 & $+12.6 *$ \\
\hline Germany & +8 & +450.0 \\
\hline Switzerland & $+12^{* *}$ & +133.3 \\
\hline India & -9 & +42.9 \\
\hline Mexico & -9 & +42.1 \\
\hline New Zealand & +4 & -33.9 \\
\hline Australia & -8 & +326.7 \\
\hline
\end{tabular}

* 2008-2014

** 2006-2014

Regarding the relationship between transparency and trust in government, the data presented in Table 5 will help to answer the two questions put forward by Fivat and Pasquier (2014). First, the data do not prove that greater transparency (in terms of FOI laws and total requests) generates greater trust in government in all states considered here. As already raised above, trust in government certainly depends on other factors - institutional, historical and political - but most of the time transparency is presented as having a positive impact on trust in government. However, data show that even in some countries where transparency has been enhanced, trust in government has declined significantly. Indeed, Mexico and India have experienced a sharp increase in requests submitted to the administration and score relatively high on open-data indexes, but levels of trust in government have dropped by 9 percentage points in both countries between 2007 and 2014. Based on this observation, the interpretation which can be drawn is rather general: effects of transparency on trust in government should not be overestimated. 
The absence of direct association between the two does not mean that there is no positive impact of transparency policies, but they remain relatively low compared to other factors. At the same time, one could also argue that transparency has no significant effect on trust in government, as shown by previous experiments (Grimmelikhuijsen 2012). Secondly, is transparency considered a remedy for declining trust in government? The data presented in this article tend to prove that trust in government is not declining on a large scale, leading us to refute this argument. Other factors have played a crucial role in the enforcement of transparency rules, once again based on historical and institutional roots. The need for more accountable and participatory governments, the growing perception of access to information as a fundamental human right, now supported by the development of new technologies, have all contributed to the global praise for transparency. Therefore, trust in government should not always be seen as an objective or supposed beneficial effect of transparency because such an effect is still to be proven empirically. However, other studies suggest that the relationship between transparency and trust in government could be investigated in another perspective: benefits to opening government data are better appreciated among citizens who have a higher level of initial trust in government. ${ }^{13}$ According to these studies, trust should not be regarded primarily as an effect of transparency, but rather as a determinant of perceived transparency from the citizens.

\section{Key findings}

In this article, data about requests submitted to public bodies and indexes of open government data have been merged for the first time. To our knowledge, there was no general dataset about requests for all the states where data is available, nor an attempt to compare this data (considered passive transparency) with active transparency. Proactive disclosure of information, including open data, was measured here with the two indexes developed by the OECD and the GOD. In spite of different methodologies and various categories, results of the rankings appeared somewhat similar. In terms of ATI requests (per 1000 inhabitants), the US, Canada and Australia are the top 3 countries, well ahead of other countries, which have adopted a legislation recently, especially Germany and Switzerland. Based on this observation, we are able to establish four categories. The first one, where countries have adopted FOI laws a long time ago and which score relatively high on both opendata indexes, include the US, Canada and Australia. The second category refers to the states that have adopted FOI laws quite recently, but have experienced a sharp increase of requests and also belong to the best nations in terms of release of public-sector data (the UK, India and Mexico). The third category includes only New

13 Pew Research Center, April 2015, "Americans' Views on Open Government Data." Available at http://www.pewinternet.org/2015/04/21/open-government-data/ (last accessed 23 January 2016). 
Zealand, where such a law was enacted in 1982, but where the number of requests has remained limited so far. On the OECD index, New Zealand scores just above the OECD average. The last group of countries is composed of Ireland, Germany and Switzerland. Although Ireland had already adopted a FOI law in 1998, all three states still have relatively recent legislation about transparency. The total amount of requests does not reach more than 0.45 per 1000 inhabitants, well behind all other countries (apart from New Zealand), and they also score relatively poorly in opendata rankings.

As shown above, data about trust in government over the last few years do not indicate a tendency towards a sharp decline in all countries, though often highlighted in the normative literature. Only half of the states considered in this article have experienced a decrease, while the other half has seen an increase for the period 2007-2014, with Switzerland gaining up to 12 points according to the OECD (2006-2014). An analysis of both data about trust in government and sets of countries mentioned above show no direct association. Indeed, while the UK, India and Mexico belong to the same "transparency group", levels of trust in government change completely among the three countries: trust in government has gained 1 percentage point in the UK and dropped by 9 points in both India and Mexico. The same phenomenon is observed in the group formed by the US, Canada and Australia, where trust in government has strongly decreased in Canada, but has not dropped dramatically in the US. A comparison between the evolution of requests submitted by citizens to public bodies and trust in government (2007-2014) also tends to prove that there is no association between both variables at the international level (see Table 5). For instance, the number of requests in Canada has gained $92 \%$, compared to $35.2 \%$ in the UK, but trust in Canada has decreased and grown in the UK. At the same time, New Zealand has experienced greater trust in government, but the number of requests has dropped by almost $34 \%$ (it is the only country to have a negative ratio).

In a comparative perspective, each country can be assigned a rank based on how they perform compared to other states in the two transparency dimensions, active and passive. India cannot be included in the following graph, since it does not appear on the OECD index. Data for New Zealand in the GOD comes from the 2014 index. For instance, on a 1-9 scale, Canada receives 8 points because it has the second highest number of ATI requests per 1000 inhabitants compared to other countries (in 2014), 7 points as it scores third on the OECD index, and 4 points as it is only ranked sixth on the GOD index. As a result, Canada scores 6.33 points on average. In comparison, Australia and the UK are the countries with the highest score (7.67) and Switzerland the lowest (1.67). Graph 1 below situates countries according to their transparency performance and their level of trust in government in 2014. It tends to show a rather negative relation between transparency and trust with the outlier being Ireland, which was in a huge economic crisis at the time and where both the transparency score and trust in government are low. Apart from the 
Irish case, it may be suggested that more information asked about the workings of the authorities could be indicative for the mistrust of citizens. Or the more one distrusts government, the more information one is likely to request about its workings. Consequently, mis(trust) in government could be addressed not only as a dependent variable; it may well be considered as a key driver in its relation with transparency. In this sense, mistrust would call for more transparency. This hypothesis (still to be proven empirically) involves reverse thinking: it is not the low level of transparency that leads to less trust from the citizens, but rather the initial level of the population's mistrust in public authorities that triggers more requests for access to official documents and a more proactive transparency policy from the government.

\section{Graph 1}

Transparency score and trust in government (in \%), 2014

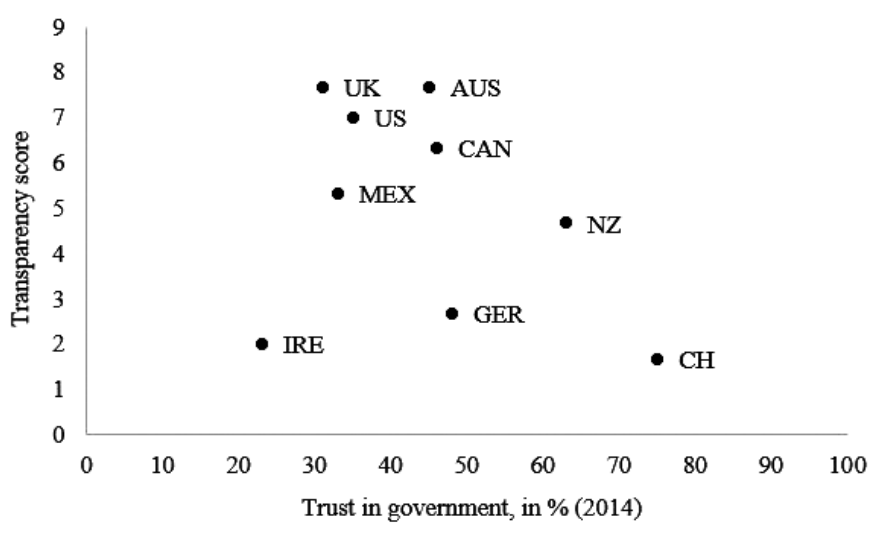

\section{Conclusion}

In conclusion, the expected positive association between transparency and trust in government is not supported by this research. Although it is necessary to take the limitations of this study into consideration, this article challenges the common normative assumption which always postulates a positive effect of transparency on trust in government.

As to the limitations, first of all, data used in this article come from various sources, as data about trust in government come from Eurobarometer surveys and from Gallup polls (published in OECD reports), while data about transparency come from two indexes and our own comparative dataset on ATI requests. As such, this study is not based on a single dataset and a unique population. Secondly, other factors, which have a potential effect on trust in government, are not considered in this study. They include interest and participation in politics, political prefer- 
ences and party affiliations (Citrin 1974), evaluation of the economy, homicide rates, international affairs and political scandals (Chanley et al. 2000). Moreover, these factors are related to contextual issues and restrict the scope to regional or national studies. Consequently, it seems difficult to draw any association between transparency and trust in government or even isolate the relationship between the two concepts, as a single dataset, including exogenous variables, is lacking. A more rigorous analysis, including more countries, and using (non-parametric) statistics would probably show that the relation between transparency and trust is not linear, as is often expected. Nevertheless, in a comparative perspective, such a study requires larger access to data and a unique set of data. This is certainly an interesting path for further research, but it involves cost and feasibility issues.

Other limitations involve definition issues. Indeed, measurement of transparency heavily depends on the dimensions considered. Until now, most measurements have only included one dimension of transparency, active (through experiments, e.g. Grimmelikhuijsen 2012, or open-data rankings) or passive (ATI requests). In a comparative perspective, we have tried to merge ATI requests and open-data indexes in this article. However, both previous studies and ours do not take into account forced transparency (Pasquier 2011), a different kind of transparency, based on whistleblowing acts. Though such acts remain relatively rare, they may have an effect on trust in government and should be looked at more closely in further research. The robustness of the data about trust in government can also be questioned, since figures vary from one survey to another. In this case, Gallup polls have been preferred for countries outside the EU but members of the OECD, and Eurobarometers have been selected for EU member states. However, alternative sources exist, such as the Edelman trust barometer ${ }^{14}$ or surveys conducted by the media. ${ }^{15}$ For instance, data about trust in government in the US in 2014 can vary from $35 \%$ down to $24 \%$. Moreover, questions asked do not distinguish trust from confidence. They do not consider the dimensions of perceived trustworthiness (competence, probity, benevolence) but keep it rather simple with one encompassing question. Such a question remains vague and may lead to confusion as a result of its high level of abstraction.

Moreover, international institutions such as the OECD do not address the issue of transparency as such but rather insist on open government. The combination of open government rankings and trust in government in 2014 shows no positive and systematic association; this is also the case with open-data indexes provided by non-profit organisations. This comment applies equally well to most Central Eu-

14 Available at http://www.edelman.com/ (last accessed 25 January 2016).

15 See for instance the New York Times article "The Long Decline of Trust in Government, and Why That Can Be Patriotic", which is based on data from ABC/Washington Post, CBS/New York Times, CNN, Gallup, A.N.E.S. and Pew Research Center. Available at http://www.nytimes. com/2015/07/04/upshot/the-long-decline-of-trust-in-government-and-why-that-can-be-patriotic.html?_r=0 (last accessed 17 January 2016). 
ropean countries. ${ }^{16}$ The same tendency is observed with respect to the evolution of ATI requests and trust in government over the last few years. However, since they are strongly linked to other factors like participation and political interest and knowledge, they have been used here in combination with open government and open data in a comparative perspective. Further research could build on these preliminary results. It may lead to the creation of a transparency index, including existing data about both active and passive transparency.

More research into this issue is therefore welcome. At this stage, we can only assert that transparency is not necessarily positively associated with trust in government (compared to other factors), as is often assumed. That conclusion is important enough in itself. The relation could also be reverse. Lacking trust calls for more transparency and does result in higher levels of passive transparency. This is understandable since the anger provoked by the revelation of political scandals, and the growing demands for more openness emanating from civil society organisations, have made the right to know an important concern in most Western states.

\section{References}

Adams, B. D. 2005. Trust vs. Confidence. Paper prepared on behalf of the Department of National Defence, June 28, in Toronto, Canada, 1-14.

Birkinshaw, P. 2006. "Freedom of Information and Openness: Fundamental Human Rights?” Administrative Law Review 58(1), 177-218.

Blomqvist, K. 1997. “The Many Faces of Trust." Scandinavian Journal of Management 13(3), 271-286.

Bouckaert, G. 2012. "Trust and Public Administration." Administration 60(1), 91-115.

Bouckaert, G. and S. Van de Walle. 2003. "Comparing Measures of Citizen Trust and User Satisfaction as Indicators of 'Good Governance': Difficulties in Linking Trust and Satisfaction Indicators." International Review of Administrative Sciences 69(3), 329-343.

Bozzo-Rey, M. 2011. "La transparence chez Jeremy Bentham: de l'invisibilité d'un concept à sa publicité." La revue Tocqueville 32(1), 89-111.

16 In Slovakia, trust in government reaches $31 \%$, and the country's score on the OECD Open government data Index is 0.33. In comparison, Slovenia's score is higher (0.48), but the level of trust in government is much lower (18\%). It should also be noted that Slovenia, in spite of its poor level of trust in government, is ranked second in the Global Right to Information Rating (https://www.rti-rating.org/). Unfortunately, there is no data available for the Czech Republic and Hungary in the OECD report, states where the level of trust in government is similar $(33 \%$ and $34 \%$ ). In Poland, $25 \%$ of the population say they trust their government, and the country scores poorly on the OECD Open government data Index (0.13). 
Brin, D. 1998. The Transparent Society. Reading, MA, USA: Addison-Wesley Longman.

Brown, A. J., W. Vandekerckhove and S. Dreyfus. 2014. "The Relationship between Transparency, Whistleblowing, and Public Trust." In P. Ala'i and R. G. Vaughn (eds). Research Handbook on Transparency. Cheltenham, UK, Northampton, MA, USA: Edward Elgar, 30-58.

Carter, L. and F. Bélanger. 2005. "The Utilization of e-Government Services: Citizen Trust, Innovation and Acceptance Factors." Information Systems Journal 15(1), 5-25.

Chanley, V. A., T. J. Rudolph and W. M. Rahn. 2000. "The Origins and Consequences of Public Trust in Government: A Time Series Analysis." Public Opinion Quarterly 64(3), 239-256.

Citrin, J. 1974. "Comment: The Political Relevance of Trust in Government." The American Political Science Review 68(3), 973-988.

Curtin, D. and A. Meijer. 2006. "Does Transparency Strenghten Legitimacy? A Critical Analysis of European Union Policy Documents." Information Polity 11, 109-122.

Edelenbos, J. and E.-H. Klijn. 2007. “Trust in Complex Decision-Making Networks: A Theoretical and Empirical Exploration." Administration \& Society 39(1), $25-50$.

Erkkilä, T. 2012. Government Transparency: Impacts and Unintended Consequences. Basingstoke: Palgrave Macmillan.

Fivat, E. and M. Pasquier. 2014. "Peut-on faire confiance à l'administration? Une analyse du concept de confiance, appliqué au secteur public." In IDHEAP (ed.). Working papers de l'IDHEAP. Lausanne: IDHEAP, Vol. 2, 62.

Florini, A. 1998. “The End of Secrecy." Foreign Policy 111, 50-63.

Giddens, A. 1984. The Constitution of Society: Outline of the Theory of Structuration. Berkeley and Los Angeles: University of California Press.

Grimmelikhuijsen, S. G. 2012. Transparency and Trust: An Experimental Study of Online Disclosure and Trust in Government. PhD thesis. University of Utrecht.

Hardin, R. 1999. “Do we Want Trust in Government?” In M. E. Warren (ed.), Democracy \& Trust. Cambridge: Cambridge University Press, 22-41.

Hardin, R. 2013. “Government without Trust." Journal of Trust Research 3(1), 32-52.

Hazell, R., B. Worthy and G. Bourke. 2009. Measuring Access to Information. Report prepared for the World Bank. London, The Constitution Unit, UCL.

Heald, D. and C. Hood (eds). 2006. Transparency: The Key to Better Governance? Vol. 135. Oxford: Oxford University Press. 
Holsen, S. 2012. Insight into Oversight: How Information Commissioners Contribute to the Achievement of ATI Policy Objectives. PhD thesis. IDHEAP.

Hood, C. 2006. “Transparency in Historical Perspective.” In D. Heald and C. Hood (eds). Transparency: The Key to Better Governance? Oxford: Oxford University Press, 3-23.

Lenaerts, K. 2004. “'In the Union we Trust': Trust-Enhancing Principles of Community Law." Common Market Law Review 41(2), 317-343.

Levi, M. and L. Stoker. 2000. "Political Trust and Trustworthiness." Annual Review of Political Science 3(1), 475-507.

Mabillard, V. and Pasquier, M. 2015. “Transparency and Trust in Government: A Two-Way Relationship." In A. Bergmann (ed). Yearbook of Swiss Administrative Sciences. Zurich: kdmz, 23-34.

Mayer, R. C., J. H. Davis and F. D. Schoorman. 1995. “An Integrative Model of Organizational Trust.” Academy of Management Review 20(3), 709-734.

McIntosh, T. 2014). "Paraguay is $100^{\text {th }}$ Nation to Pass FOI Law, but Struggle for Openness Goes on.” The Guardian, 19 September 2014.

Meijer, A., D. Curtin and M. Hillebrandt. 2012. “Open Government: Connecting Vision and Voice." International Review of Administrative Sciences 78(1), 10-29.

Meilland, P. 2013. “Caractéristiques des lois sur l'accès à l'information en Suisse." In M. Pasquier (ed.). Le principe de transparence en Suisse et dans le monde. Lausanne \& Berne: PPUR \& Haupt, 19-35.

Möllering, G. 2013. “Trust without Knowledge? Comment on Hardin, 'Government without Trust." Journal of Trust Research 3(1), 53-58.

OECD. 2015. Government at a Glance 2015. Paris: OECD Publishing.

Pasquier, M. 2009. "La mise en oeuvre de la loi sur la transparence: absence d'intérêts des citoyens ou particularités du système suisse?” In R. T. Trindade, H. Peter and C. Bovet (eds). Economie Environnement Ethique. De la responsabilité sociale et sociétale. Genève, Zurich: Schulthess, 281-288.

Pasquier, M. 2011. Communication publique. Brussels: De Boeck.

Pasquier, M. (ed.). 2013. Le principe de transparence en Suisse et dans le monde. Lausanne et Berne: PPUR \& Haupt.

Pasquier, M. and S. Holsen. 2009. “The Swiss Federal Law on Transparency: Much Ado about nothing?" In T. Brandsen and M. Holzer (eds). The Future of Governance: Selected Papers from $5^{\text {th }}$ Transatlantic Dialogue on Public Administration. Newark, NJ: National Center for Public Performance (NCPP), 151-167. 
Pasquier, M., and J.-P. Villeneuve. 2007. "Organizational Barriers to Transparency: A Typology and Analysis of Organizational Behaviour Tending to Prevent or Restrict Access to Information." International Review of Administrative Sciences 73(1), 147-162.

Rawlins, B. R. 2009. "Give the Emperor a Mirror: Toward Developing a Stakeholder Measurement of Organizational Transparency." Journal of Public Relations Research 21(1), 71-99.

Roberts, A. 2010. "A Great and Revolutionary Law? The First Four Years of India's Right to Information Act." Public Administration Review 70(6), 925-933.

Sako, M. and S. Helper. 1998. "Determinants of Trust in Supplier Relations: Evidence from the Automotive Industry in Japan and the United States." Journal of Economic Behavior \& Organization 34(3), 387-417.

Shaw, R. 1997. Trust in the Balance. New York: John Wiley.

Stasavage, D. 2003. "Transparency, Democratic Accountability, and the Economic Consequences of Monetary Institutions." American Journal of Political Science 47(3), 389-402.

Strathern, M. 2000. "The Tyranny of Transparency." British Educational Research Journal 26(3), 309-321.

Sullivan, A. 1965. "Values in Public Relations." In O. Lerbinger and A. Sullivan (eds). Information, Influence, and Communication: A Reader in Public Relations. New York: Basic Books, 412-439.

Van de Walle, S., S. Van Roosbroek and G. Bouckaert. 2008. "Trust in the Public Sector: Is there any Evidence for a Long-Term Decline?" International Review of Administrative Sciences 74(1), 47-64.

Worthy, B. 2010. "More Open but not more Trusted? The Effect of the Freedom of Information Act 2000 on the United Kingdom Central Government." Governance 23(4), 561-582.

Zaheer, A., B. McEvily and V. Perrone. 1998. "Does Trust Matter? Exploring the Effects of Interorganizational and Interpersonal Trust on Performance." Organization Science 9(2), 141-159.

Zand, D. E. 1971. “Trust and Managerial Problem Solving." Administrative Science Quarterly 17, 229-239.

Zucker, L. G. 1986. "Production of Trust: Institutional Sources of Economic Structure, 1840-1920." In B. M. Staw and L. L. Cummings (eds). Research in Organizational Behavior. Greenwich, CT: JAI Press, 53-111. 